Published in: Mater. Sci. Techn., Vol 23, 2007, 1419-1423

\title{
A comparison of high temperature fatigue crack propagation in various sub- solvus heat treated turbine disc alloys
}

\author{
S. Everitt, M.J. Starink, H.T. Pang*, I.M. Wilcock**, M.B. Henderson*** and P.A.S. Reed \\ Materials Research Group, School of Engineering Sciences, University of Southampton, \\ Southampton SO17 1BJ, UK \\ * currently at Dept. Materials Science and Metallurgy, University of Cambridge, Cambridge, UK

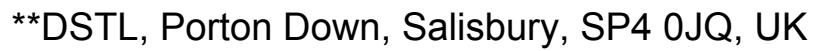 \\ ${ }^{* * *}$ ALSTOM, Rugby, Warwickshire, CV21 2NH, UK
}

\begin{abstract}
The microstructure and fatigue performance of three sub-solvus heat treated nickel based disc superalloys for turbine disc applications are reported. The alloy variants studied are RR1000, N18 and Udimet 720 Low Interstitial (U720Li), with the latter tested both in a standard and large grain variant (LG). Their microstructures are examined in terms of grain and gamma prime size $\left(\gamma^{\prime}\right)$. Fatigue crack growth (FCG) rates for all materials at $650^{\circ} \mathrm{C}$ show that RR 1000 provides the best performance, followed by U720Li-LG, N18 and U720Li. Some of the variations in FCG rate between the alloys are due to reduction in grain boundary oxidation processes with increased grain size, but more subtle interplays between grain boundary character, alloy composition and slip character are also important.
\end{abstract}

\section{INTRODUCTION}

Gas turbine discs experience differing service conditions across the component ranging from temperatures of around $300^{\circ} \mathrm{C}$ and relatively high stresses at the bore to higher temperatures of around $650^{\circ} \mathrm{C}$ and somewhat lower stresses at the rim. Stress concentration features such as fir tree root fixings at the rim further increase the need for excellent high temperature damage tolerance in view of the cyclic loading experienced by these components ${ }^{1}$. Most turbine discs are now manufactured from nickel base superalloys due to their good resistance against combinations of fatigue, creep, oxidation and corrosion damage. At higher temperatures, above $500^{\circ} \mathrm{C}$, previous research ${ }^{2}$ has shown that failure occurs predominantly by intergranular crack propagation. The rate at which this progresses is controlled by microstructural features of the material such as grain size, grain boundary character and the amount, size and coherency of the 
gamma prime $\left(\gamma^{\prime}\right)$ precipitates in the material. These features are controlled by both alloy chemistry and subsequent heat treatments.

This paper presents the results of high temperature fatigue tests carried out in air at $650^{\circ} \mathrm{C}$ on the N18 Ni based superalloy and compares them to three different Ni based superalloys. N18 is a powder metallurgy (PM) turbine disc material, developed for the SNECMA M88 engine used in the RAFALE aircraft, however it differs from other new generation PM turbine disc alloys in both composition and heat treatment, and thus provides the opportunity to assess the differing effects of precipitate morphology and grain size. The three comparator alloys are RR1000 ${ }^{3}$, Udimet 720Li (U720Li) ${ }^{4}$ and U720Li Large Grain (U720Li-LG) variant ${ }^{4,5}$. U720Li is a variant of the U720 alloy designed to minimise the formation of topologically closed packed phases which are detrimental to the properties, and U720Li-LG is an experimental variant produced by solution heat treating U720Li at a somewhat higher temperature. The influence of composition, sub-solvus heat treatments and cooling rates, along with the resultant grain size and $\gamma^{\prime}$ size and distribution on fatigue crack propagation behaviour are compared and contrasted.

\section{MATERIALS AND EXPERIMENTAL PROCEDURE}

The compositions of the three alloys studied are presented in Table 1 and the heat treatments applied are presented in Table 2. The RR1000 alloy studied is an early generation version of this alloy.

To allow optical microscopy and scanning electron microscopy (SEM) studies of the microstructure of the materials, specimens were mounted in Bakelite, polished to a $1 \mu \mathrm{m}$ finish using standard metallographic techniques, and then electrolytically etched using an orthophosphoric acid solution typically for 3 to 4 seconds. Micrographs were obtained using both an Olympus BH-2 optical microscope and a JSM 6500F field emission gun scanning electron microscope (FEG-SEM) and grain sizes were estimated using automatic image analysis software or the line-intercept method. Further characterisation of secondary and tertiary $\gamma^{\prime}$ was carried out by creating either carbon replicas or thin film samples and analysing these in a JEOL JEM 3010 transmission electron microscope (TEM).

N18 fatigue testing was carried out using a servo-hydraulic Instron 8501 fitted with an ESH high temperature vacuum chamber. Testing was carried out in three point bend conditions on single edge notched bend specimens (SENB). Fatigue testing of RR1000, U720Li and U720Li-LG was carried out using compact tension (CT) test specimens. For all materials, temperature was 
monitored and controlled at $650^{\circ} \mathrm{C} \pm 2^{\circ} \mathrm{C}$. After precracking, cracks were propagated using an initial $\Delta K$ of $15 \mathrm{MPa} \sqrt{\mathrm{m}}$ using a 1-1-1-1 trapezoidal waveform $(0.25 \mathrm{~Hz}), \mathrm{R}=0.1$ and were allowed to propagate to failure under constant load (increasing $\Delta K$ conditions). Crack length was monitored using the direct current (DC) electrical potential difference (p.d.) method and corrected post-test using a linear correction factor obtained from optical measurements of initial and final crack length measurement. Fracture surfaces were examined post-failure in the FEGSEM.

Table 1 Composition of alloys.

\begin{tabular}{|c|c|c|c|c|c|c|c|c|c|c|c|c|}
\hline Alloy & $\begin{array}{c}\text { Co } \\
\text { (wt. \%) }\end{array}$ & $\begin{array}{c}\mathrm{Cr} \\
\text { (wt. \%) }\end{array}$ & $\begin{array}{c}\text { Mo } \\
\text { (wt. \%) }\end{array}$ & $\begin{array}{c}\mathrm{Al} \\
\text { (wt. \%) }\end{array}$ & $\begin{array}{c}\mathrm{Ti} \\
\text { (wt. \%) }\end{array}$ & $\begin{array}{c}\text { Hf } \\
\text { (wt. \%) }\end{array}$ & $\begin{array}{c}\mathrm{C} \\
\text { (wt. \%) }\end{array}$ & $\begin{array}{c}\text { B } \\
\text { (wt. \%) }\end{array}$ & $\begin{array}{c}\mathrm{W} \\
\text { (wt. \%) }\end{array}$ & $\begin{array}{c}\mathrm{Fe} \\
\text { (wt. \%) }\end{array}$ & $\begin{array}{c}\mathrm{Zr} \\
\text { (wt. \%) }\end{array}$ & \begin{tabular}{|c}
$\mathrm{Ta}$ \\
(wt. \%)
\end{tabular} \\
\hline N18 & 15.4 & 11.1 & 6.44 & 4.28 & 4.28 & 0.50 & 0.022 & 0.008 & -- & --- & 0.019 & -- \\
\hline RR1000 & $\begin{array}{l}14.0- \\
19.0\end{array}$ & $\begin{array}{l}14.35- \\
15.15 \\
\end{array}$ & $\begin{array}{l}4.25- \\
5.25 \\
\end{array}$ & $\begin{array}{l}2.85- \\
3.15 \\
\end{array}$ & $\begin{array}{c}3.45- \\
4.15 \\
\end{array}$ & $0.5-1.0$ & $\begin{array}{c}0.012- \\
0.033 \\
\end{array}$ & $\begin{array}{l}0.01- \\
0.025\end{array}$ & --- & $0.0-1.0$ & $\begin{array}{l}0.05- \\
0.07\end{array}$ & $\begin{array}{l}1.35- \\
2.15\end{array}$ \\
\hline U720Li \& LG & 14.57 & 15.92 & 2.98 & 2.44 & 5.18 & --- & 0.023 & 0.016 & 1.35 & 0.08 & 0.042 & --- \\
\hline
\end{tabular}

Table 2 Material yield strength, $\gamma^{\prime}$ solvus (as quoted in the literature) and heat treatment comparison at $650^{\circ} \mathrm{C}$. Where two references are given a rounded average of reported values are included in the table. (* all ageing heat treatments were followed by an air cool)

\begin{tabular}{|l|c|c|cc|cc|}
\hline Alloy & $\sigma_{\mathrm{y}}$ at $650^{\circ} \mathrm{C}$ & $\gamma^{\prime}$ solvus & \multicolumn{2}{|c|}{ Solution heat treatment } & \multicolumn{2}{|c|}{ Ageing heat treatments* } \\
\hline N18 & $1031 \mathrm{MPa}^{6}$ & $1190^{\circ} \mathrm{C}^{7}$ & $4 \mathrm{~h} 1165^{\circ} \mathrm{C}$ & air cool & $24 \mathrm{~h} 700^{\circ} \mathrm{C}$ & $4 \mathrm{~h} 800^{\circ} \mathrm{C}$ \\
\hline RR1000 & $970 \mathrm{MPa}^{9}$ & $1160^{\circ} \mathrm{C}^{3,9}$ & $4 \mathrm{~h} 1120^{\circ} \mathrm{C}$ & fan air cool & $24 \mathrm{~h} 650^{\circ} \mathrm{C}$ & $16 \mathrm{~h} 760^{\circ} \mathrm{C}$ \\
\hline U720Li & $980 \mathrm{MPa}^{5}$ & $1160^{\circ} \mathrm{C}^{3,8}$ & $4 \mathrm{~h} 1105^{\circ} \mathrm{C}$ & oil quench & $24 \mathrm{~h} 650^{\circ} \mathrm{C}$ & $16 \mathrm{~h} 760^{\circ} \mathrm{C}$ \\
\hline U720Li-LG & $850 \mathrm{MPa}^{5}$ & $1160^{\circ} \mathrm{C}^{3,8}$ & $4 \mathrm{~h} 1135^{\circ} \mathrm{C}$ & air cool & $24 \mathrm{~h} 650^{\circ} \mathrm{C}$ & $16 \mathrm{~h} 760^{\circ} \mathrm{C}$ \\
\hline
\end{tabular}

\section{RESULTS}

Micrographs of the materials are shown at comparable magnifications in Fig. 1. These figures show primary incoherent $\gamma^{\prime}$ particles (light particles) decorating the grain boundaries in all alloys. The grain size of N18 and U720Li-LG are similar ranging between 4.8-41.3 $\mu \mathrm{m}$. RR1000 and U720Li have finer grain sizes ranging between 2.3-16.0 $\mu \mathrm{m}$ and 2.1-13.1 $\mu \mathrm{m}$, respectively. These two materials have essentially the same grain size distribution. Secondary $\gamma^{\prime}$ sizes were assessed in the FEG-SEM, an example is provided in Fig. 2. This assessment showed that N18 has a coarser distribution $(400-800 \mathrm{~nm})$ than RR1000 and the U720Li variants $(40-300 \mathrm{~nm})$. Tertiary $\gamma^{\prime}$ sizes were assessed in the TEM and found to be comparable for N18, RR1000 and U720Li-LG (6 $-30 \mathrm{~nm})$ whereas U720Li had a somewhat larger size range $(1-45 \mathrm{~nm})$. 
Figure 1 Optical micrographs of N18 (a), RR1000 (b), U720Li (c) and U720Li-LG (d), all after an orthophosphoric etch

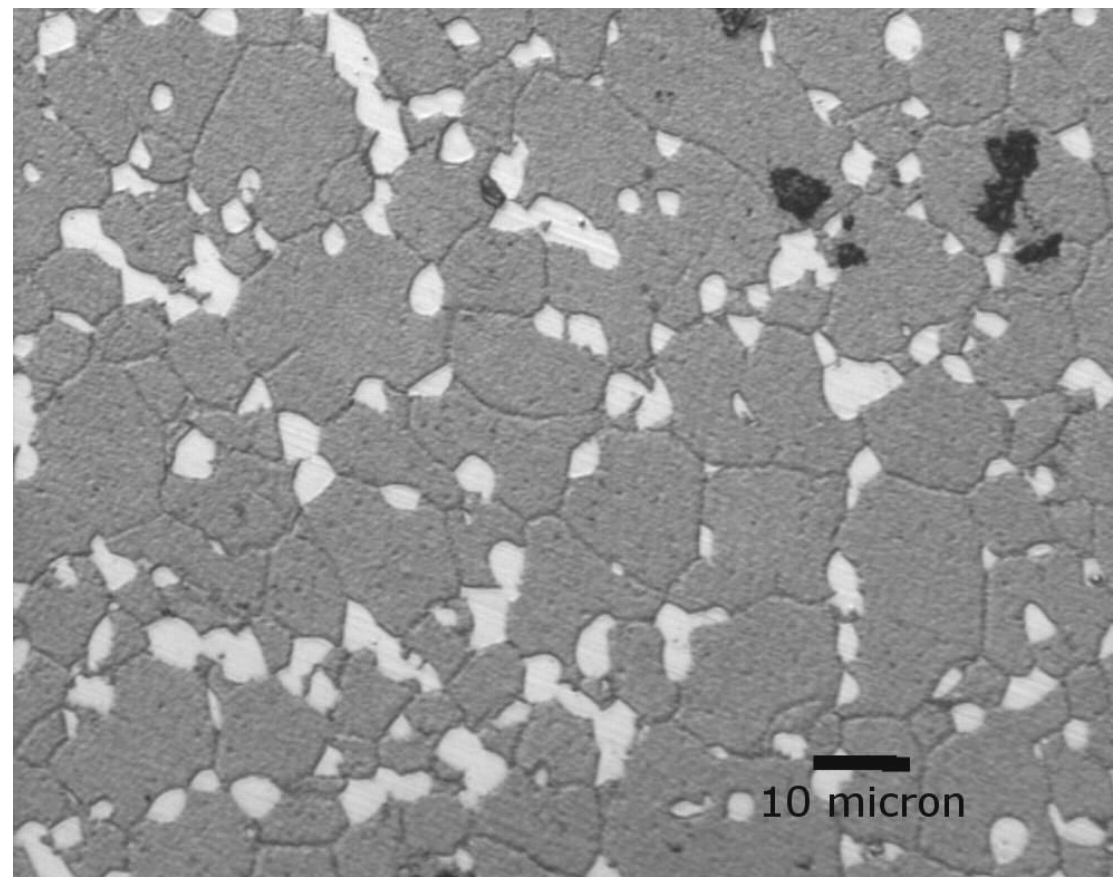

a

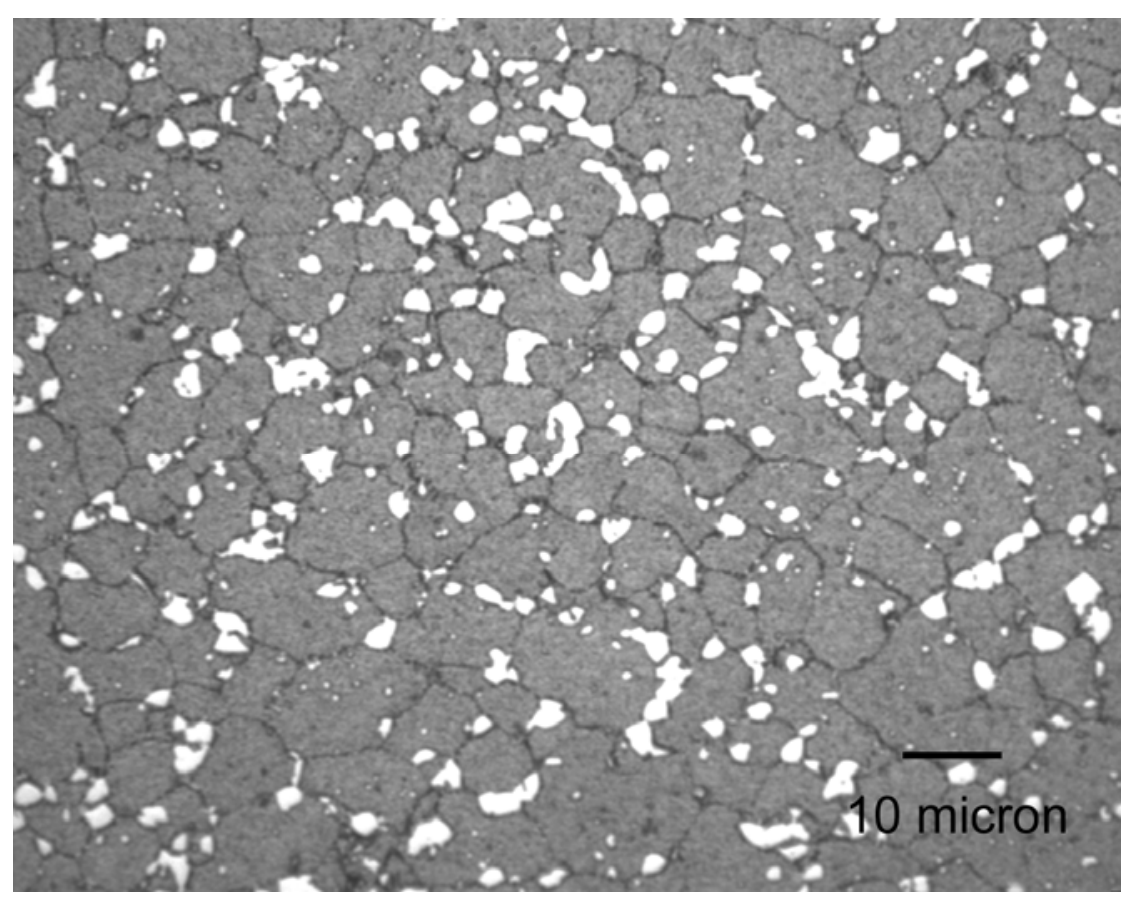

$\mathrm{b}$ 


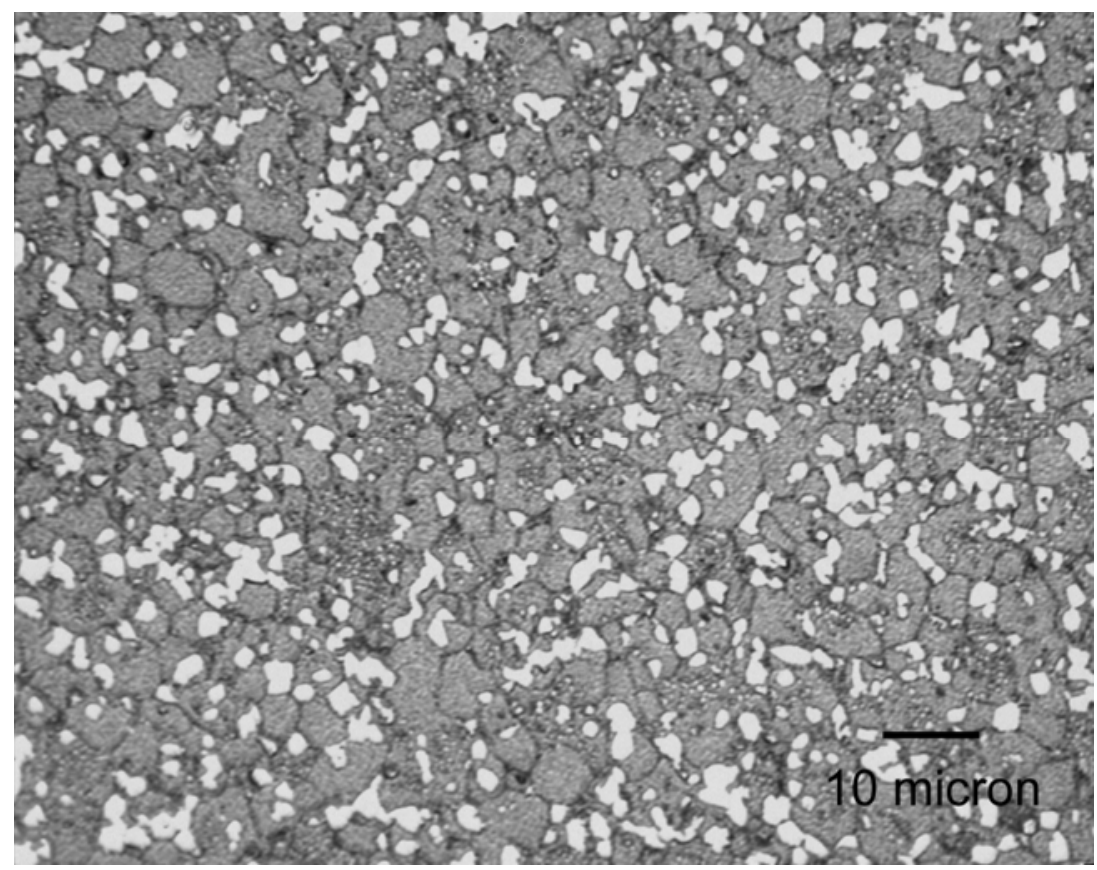

C

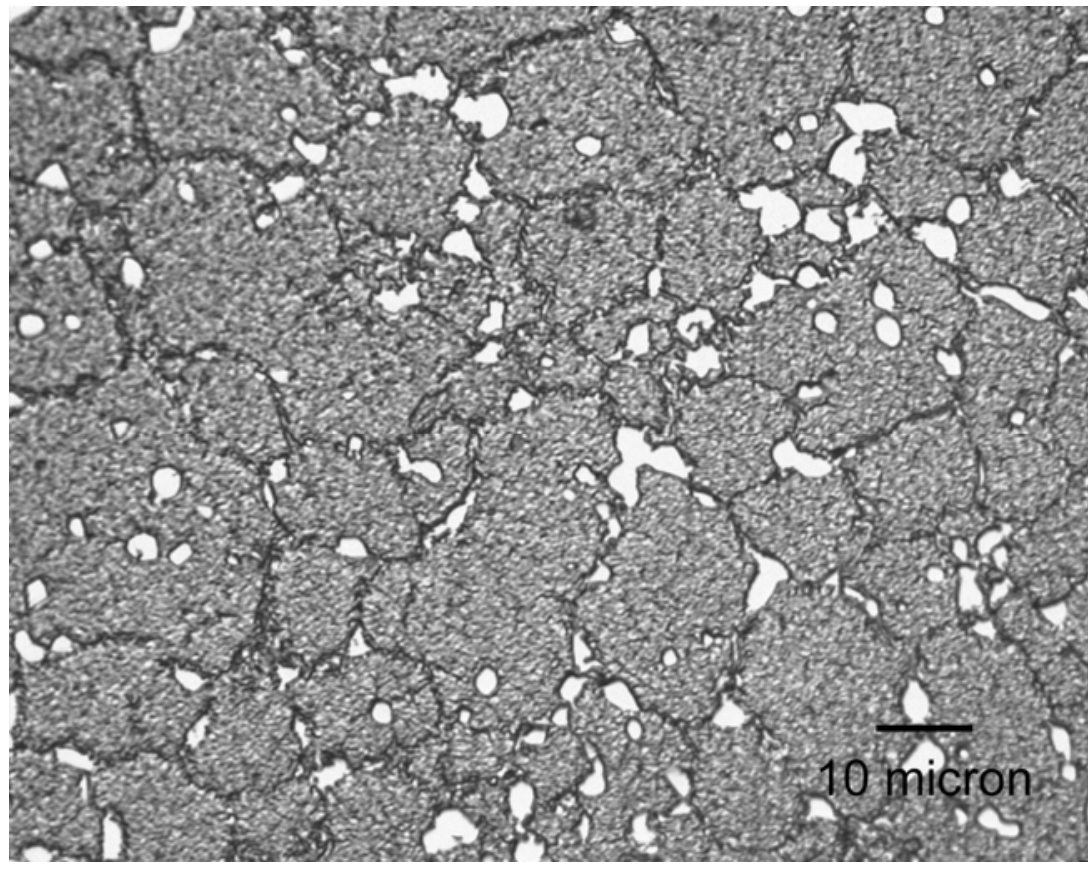

d

The crack growth rates $(\mathrm{d} a / \mathrm{d} N)$ against $\Delta K$ for all four alloys are presented in Fig. 3. RR1000 is the best performing alloy at $650^{\circ} \mathrm{C}$. The FCG resistance is next best in U720Li-LG, followed by N18 and finally U720Li displaying the worst crack propagation resistance. The micrographs of the fracture surfaces are compared in Fig. 4 (at $\Delta K \approx 20 \mathrm{MPa} \sqrt{\mathrm{m}}$ ). All micrographs show mixed transgranular and intergranular crack growth modes, although intergranular crack growth modes predominate. The RR1000 and N18 alloys show the most transgranular crack growth features at 
$650^{\circ} \mathrm{C}$ whilst U720Li has the roughest (most intergranular) fracture surfaces at both test temperatures. Additional fractography studies showed that for all materials the failure modes become increasingly intergranular with increasing $\Delta K$.

Figure 2 FEG-SEM secondary electron image of N18 etched using a Nimonic etch (12 seconds). Secondary and tertiary $\gamma^{\prime}$ has been etched out of material

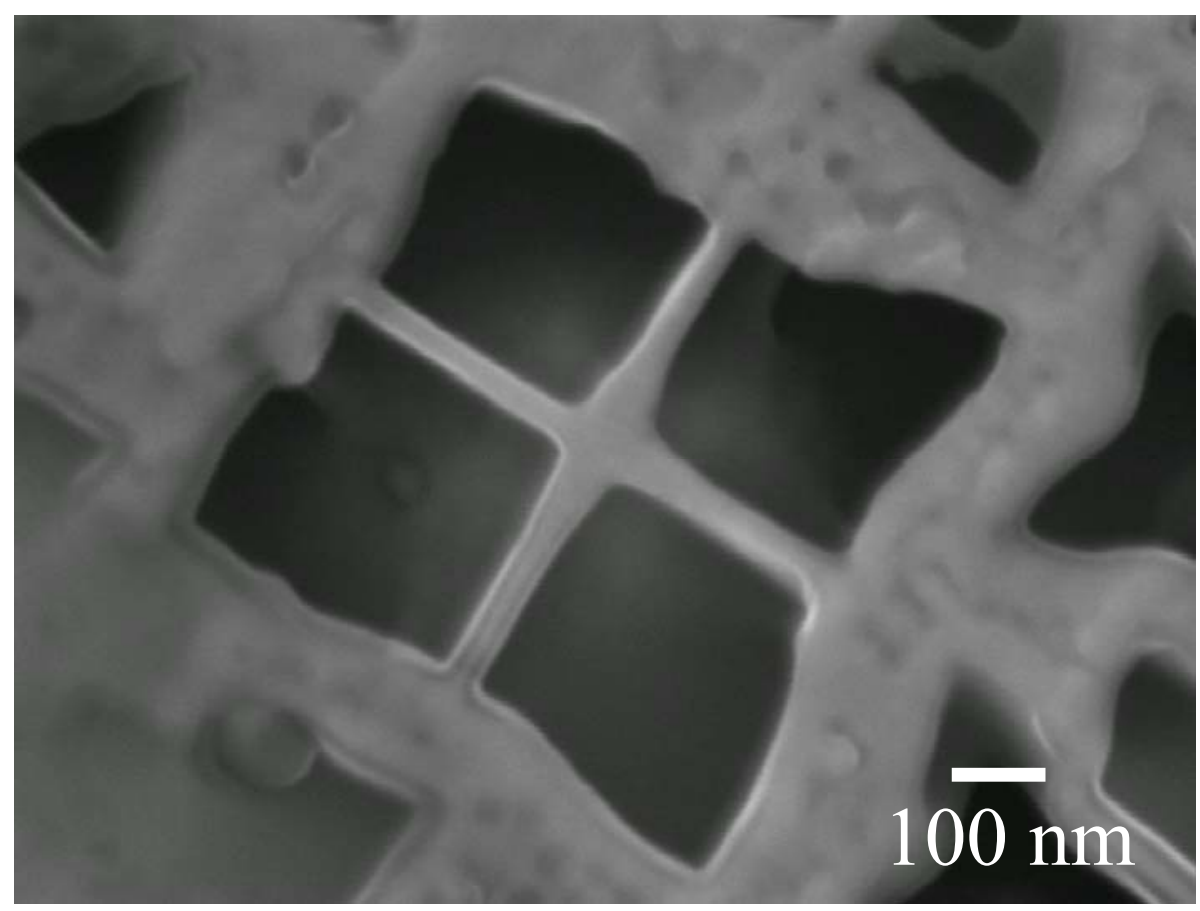

\section{DISCUSSION}

The grain and $\gamma^{\prime}$ sizes will have a significant influence on the mechanical properties of the alloys such as yield strength, creep and fatigue resistance. All alloys were given (sub-solvus) solution treatments, the $\gamma^{\prime}$ solvus temperatures for N18, U720Li and RR1000 being given in the literature as about $1190^{\circ} \mathrm{C}^{7}, 1160^{\circ} \mathrm{C}^{3,8}$ and $1160^{\circ} \mathrm{C}^{3,9}$ respectively. However, U720Li-LG, RR1000 and N18 have been solution treated relatively close to their $\gamma^{\prime}$ solvus temperature $c f$. U720Li, which has resulted in more resolutionising of primary $\gamma^{\prime}$ for U720Li-LG, RR1000 and N18. The reduced amount of primary $\gamma^{\prime}$ at the solution treatment temperature is expected to result in faster grain growth, together with an observed reduction in volume fraction of primary $\gamma^{\prime}$. However larger grain sizes are only observed in Fig. 1 for N18 and U720Li-LG, in the case of RR1000, other grain boundary pinning processes (such as carbides, see below) must be in operation as despite the reduction in primary $\gamma^{\prime}$ the grain size is still quite fine. 
Figure 3 Comparison of crack growth rates $\mathrm{d} a / \mathrm{d} n$ at $650^{\circ} \mathrm{C}$ in air of the 4 materials. $(\mathrm{d} a / \mathrm{d} n$ is normalised by a harmonic mean of observed growth rates).

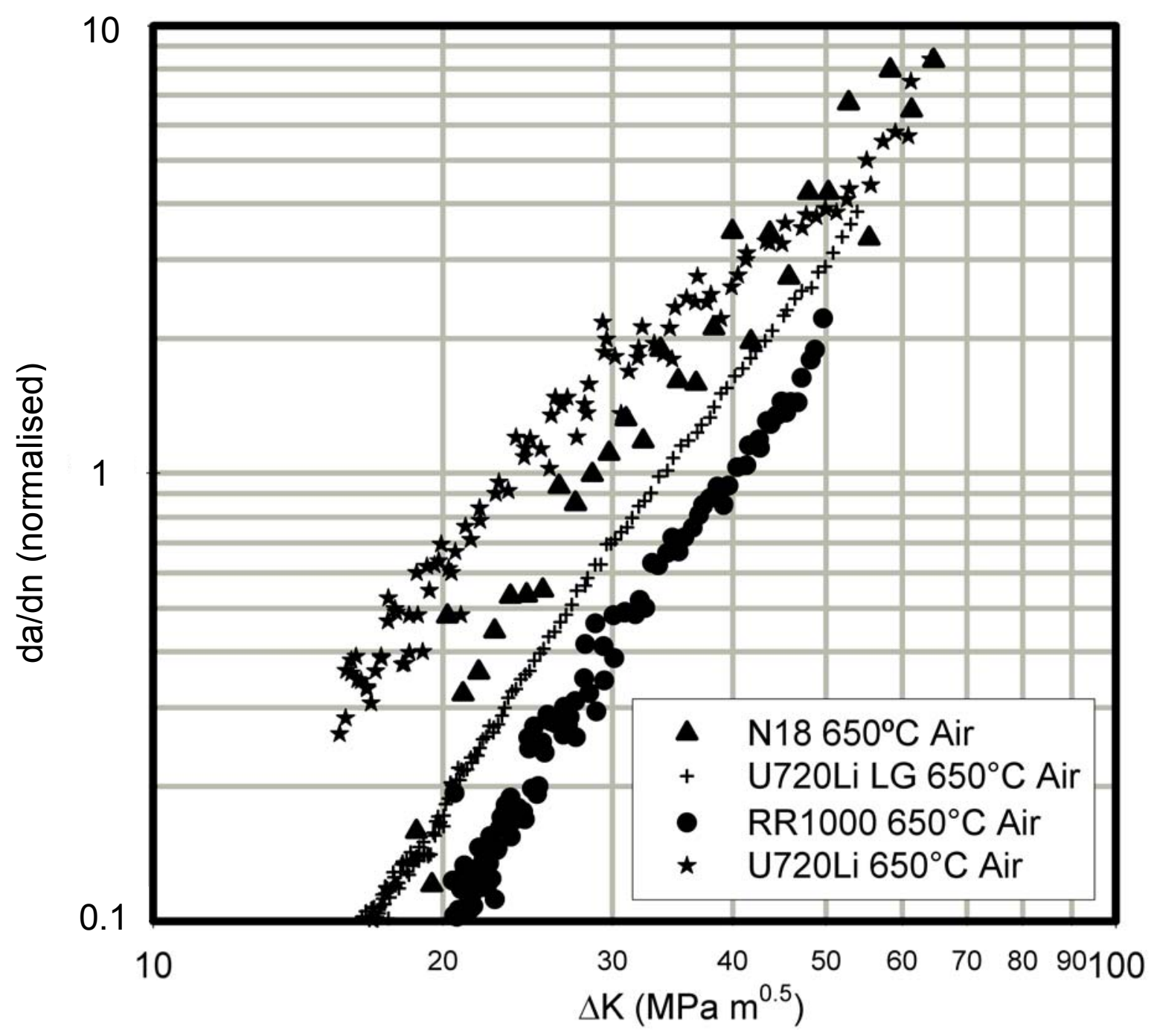

The decrease in volume fraction of primary $\gamma^{\prime}$ will leave more $\gamma^{\prime}$ forming elements available in solution to form secondary and tertiary $\gamma^{\prime}$ during subsequent ageing processes. As primary $\gamma^{\prime}$ is incoherent with the $\gamma$ matrix an increase in the amount of secondary $\gamma^{\prime}$ (which may be coherent with the matrix) should have a beneficial effect on strengthening the alloy, especially at high temperatures, although grain boundary strengthening will be reduced. Strength values at $650^{\circ} \mathrm{C}$ for the materials in the heat treated conditions listed in Table 2 are given in the same table. (Note that some of these values are estimated from non-standard tests, see references provided.) It can be seen that the strength ranking is: N18 $>\mathrm{U} 720 \mathrm{Li}>\mathrm{RR} 1000>\mathrm{U} 720 \mathrm{Li}-\mathrm{LG}-$ so N18 has a better strength performance at equivalent grain sizes to U720Li-LG. Creep and oxidation occur 
principally along grain boundaries due to the preferential diffusion paths they offer, and this weakens the grain boundary and provides a weaker path along which cracking can occur. Such creep and grain boundary oxidation effects will be reduced by the larger grain size (and hence decrease in amount of grain boundary area), but may also be expected to vary with alloy composition and grain boundary character.

In the fractography of the failed samples at $\Delta K \approx 20 \mathrm{MPa} \sqrt{\mathrm{m}}$ (Fig. $4 \mathrm{a}-\mathrm{d}$ ), N18 (Fig. 4a) exhibits the most transgranular failure on the fracture surface, followed by U720Li-LG (Fig. 4d). RR1000 (Fig. 4b) exhibits mixed intergranular and transgranular failure modes under these conditions whilst U720Li, Fig. 4c, shows mostly intergranular failure. Comparison with tests conducted in vacuum has indicated that at these temperatures oxidation-fatigue processes swamp pure creep-fatigue processes ${ }^{9}$. Further evidence of this can be seen in the fatigue crack propagation rates at $650^{\circ} \mathrm{C}$, Fig. 3, where the large grain variety of U720Li(-LG) has improved fatigue crack propagation performance over the as-received U720Li. The better crack propagation performance shown in U720Li-LG when compared with U720Li can therefore be understood in terms of reduced grain boundary area, where grain size effects alone have been varied.

N18 and U720Li-LG have similar grain sizes and amounts of primary $\gamma^{\prime}$ but the crack propagation rate for both alloys is only comparable at $\Delta K$ of $30 \mathrm{MPa} \sqrt{\mathrm{m}}$. At lower $\Delta K$ values the crack propagation rate of U720Li-LG is lower, and the slopes of the curves appear different, which is perhaps indicative of differing crack propagation mechanisms in operation due to more subtle combinations of oxidation and slip behaviour differences.

RR1000 achieves the lowest crack propagation rate over all $\Delta K$ levels and yet has a grain size intermediate between U720Li and U720Li-LG. This shows that grain size alone cannot account for the crack propagation rates across the alloys. The influence of additional factors such as alloy chemistry and coherent $\gamma^{\prime}$ distributions, which will strongly influence the alloys' flow strengths at elevated temperature, and slip behaviour may play a role in transport of oxygen to the grain boundaries $^{10}$. Previous short crack studies in some of these alloys at $650^{\circ} \mathrm{C}^{11}$ have indicated that changes in the finer $\gamma^{\prime}$ distributions and the concomitant effects on slip behaviour only have a minor effect $c f$. grain size effects. Alloy chemistry will also play an important part in the control of oxidation rates along grain boundaries in RR1000, N18 and the U720Li variants. 
Figure 4 Fracture surfaces at $\Delta K \approx 20 \mathrm{MPa} \sqrt{\mathrm{m}}$ for materials tested at $650^{\circ} \mathrm{C}$ in air, $\mathrm{N} 18$ (a), RR1000 (b), U720Li (c) and U720Li-LG (d), (FEG-SEM, secondary electron image). The arrow indicates the crack growth direction.
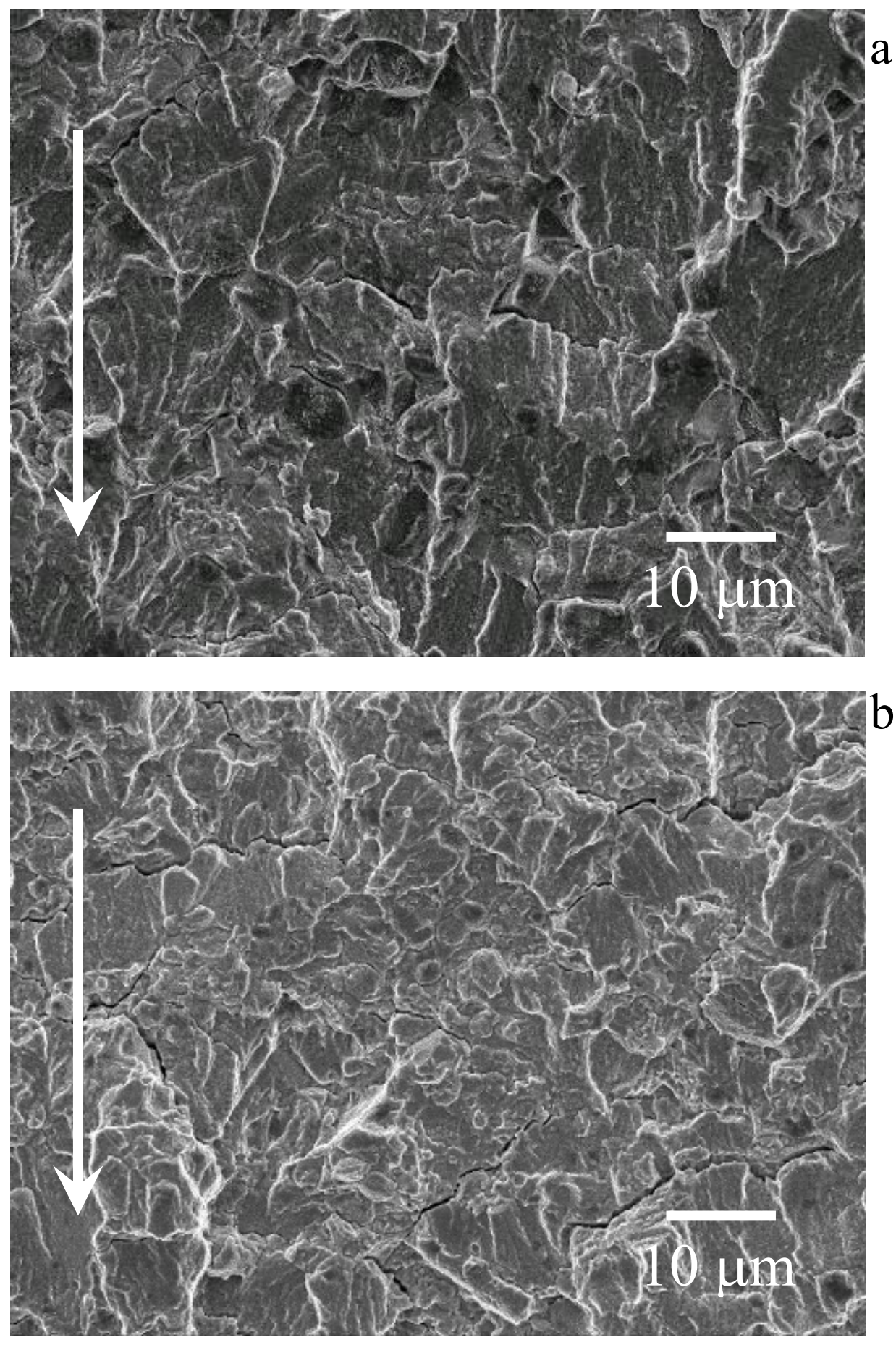

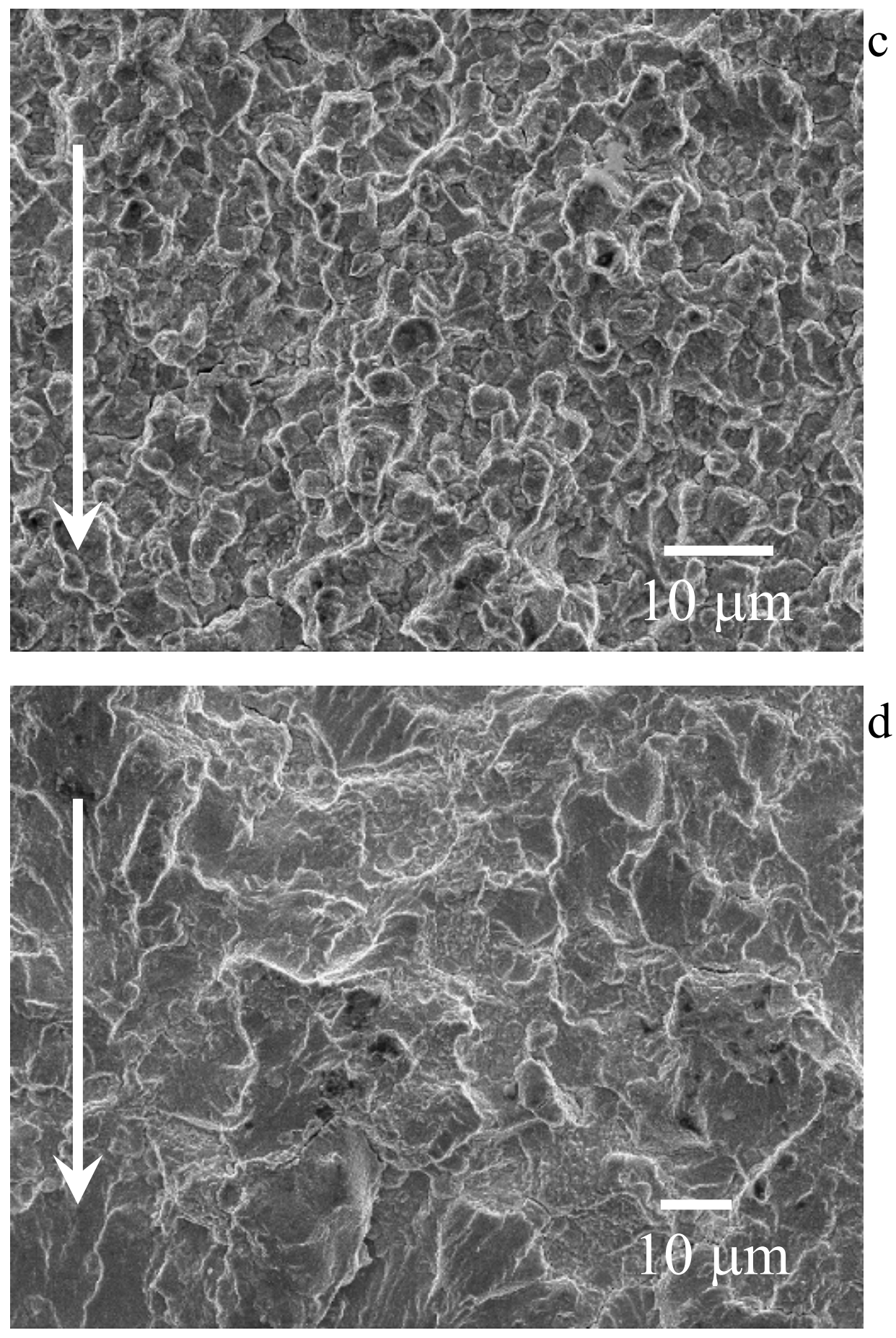

Amongst the differences in alloy chemistry, one important aspect here is the addition of Hf to the RR1000 and N18 alloys and Ta to RR1000. For fatigue resistance it is important that these elements will modify the MC carbides to become enriched in $\mathrm{Hf}$ and Ta and under certain conditions $\mathrm{MC}$ carbide with a wide range of compositions from $\mathrm{Hf}$ lean (Ti,Ta)C to $\mathrm{Hf}$ rich $\mathrm{MC}$ 
can form ${ }^{12}$. The decomposition of the MC carbides during heat treatment and exposure at high temperatures will cause the formation of lower carbides such as the $\mathrm{Cr}$-rich $\mathrm{M}_{23} \mathrm{C}_{6}$ carbides which form predominantly at grain boundaries in a range of superalloys ${ }^{13}$, including RR $1000^{14}$. As C diffusion is orders of magnitude faster than diffusion of metallic alloying elements, and Ta and Hf diffusion is particularly slow, the rate of $\mathrm{M}_{23} \mathrm{C}_{6}$ formation is dependent mostly on the decomposition rate of the Ta and $\mathrm{Hf}$ containing $\mathrm{MC}$ carbides. Thus, in combination with heat treatment schedule, Ta and $\mathrm{Hf}$ additions offer the possibility of fine tuning the $\mathrm{M}_{23} \mathrm{C}_{6}$ distribution on grain boundaries and the microchemistry of the grain boundaries. In addition, the MC carbides will to some extent be located preferentially at grain boundaries, because they slow down grain growth. These carbides at grain boundaries are expected to influence fatigue crack propagation along grain boundaries through two mechanisms. Firstly, formation of substantial amounts of the Cr-rich $\mathrm{M}_{23} \mathrm{C}_{6}$ carbides at grain boundaries will cause local $\mathrm{Cr}$ depletion of the matrix at the grain boundaries and hence change local susceptibility to corrosion and the corrosion products formed, which will degrade FCG resistance in air. This effect is also influenced by the increased Mo content of RR1000, which will substitute for some of the $\mathrm{Cr}$ in the formation of $(\mathrm{Cr}, \mathrm{Mo})_{23} \mathrm{C}_{6}$. On the other hand, the presence of carbides at grain boundaries will reduce creep by grain boundary sliding, and this effect is especially important for finer grained alloys. Thus carbides at grain boundaries will improve FCG resistance in vacuum and can improve FCG resistance in air provided the detrimental effect of $\mathrm{Cr}$ depletion is kept limited. The beneficial effect will become more important if a dwell at high load is included. It has been stated that the composition and heat treatment of RR1000 is optimised to provide the optimum grain boundary carbide distribution with optimum size of carbide grain boundary particles of 350 to $550 \mathrm{~nm}^{14}$. On the basis of the present discussion it is suggested that the superior FCG resistance of RR1000 is related to a (near) optimised combination of heat treatment and Ta and Hf additions which produces a beneficial distribution of fine carbides at grain boundaries and an beneficial local chemistry at the grain boundaries. This optimisation ultimately proves more beneficial compared to the increased grain size of the U720Li-LG variant, which is thought to have grain boundary particle distributions and chemistry that are not optimised for FCG resistance.

\section{SUMMARY}

Microstructural analysis and fatigue testing results from four materials U720Li, U720Li-LG, RR1000 and N18 have been presented. The two materials heat treated closer to the $\gamma^{\prime}$ solvus (N18 and U720Li-LG) have the largest grain sizes. In terms of fatigue crack growth at $650^{\circ} \mathrm{C}$ in air, the materials can be ranked in order of performance with RR1000 providing the best performance, followed by U720Li-LG, N18 and U720Li. In general, as $\Delta K$ levels are increased, 
the fatigue fracture surfaces show increased levels of intergranular failure, which has been attributed principally to increased intergranular oxidation fatigue effects. The larger grain size of U720Li-LG $c f$. U720Li therefore explains their relative fatigue performance. The superior performance of RR1000, which has a smaller grain size than N18 and U720Li-LG is thought to be due to the influence of other factors, such as alloy chemistry and grain boundary character (including grain boundary carbide distributions) at elevated temperatures in combination with the factors controlling oxidation rates along grain boundaries.

\section{ACKNOWLEDGEMENTS}

Thanks are due to The School of Engineering Sciences, University of Southampton, UK, the Engineering and Physical Science Research Council (EPSRC), UK and QinetiQ Ltd., Farnborough, UK for financial support. Technical discussions with Dr Jeff Brooks and Dr Irene di Martino of QinetiQ are gratefully acknowledged. Rolls-Royce are thanked for original materials supply of RR1000.

\section{REFERENCES}

1 T. Connolley, P.A.S. Reed and M.J. Starink, Mater. Sci. Eng. A, 2003, 340, 130-145

2 B.A. Lerch, N. Jayarman and S.D. Antolovich, Mater. Sci. Eng., 1984, 66,151-165

3 S.J. Hessell, W. Voice, A.W. James, S.A. Blackham, C.J. Small and M.R. Winstone, US Patent $5897718,1999$.

4 N.J. Hide, M.B. Henderson, and P.A.S. Reed, in Superalloys 2000, Proc of $9^{\text {th }}$ Inter. Symposium on Superalloys, Sept 17-21, 2000, Seven Springs, Pennsylvania, ed. T.M. Pollock, R.D. Kissinger, R.R. Bowman, K.A. Green, M. McLean, S. Olson and J.J. Scirra, TMS (The Minerals, Metals and Materials Society, ASM), 495-503

5 H.T. Pang and P.A.S. Reed, Mater. Sci. Eng. A, 2007, 448, 67-79

6 A.Wisbey, I.Di Martino, J.W.Brooks, S. Everitt and P.A.S. Reed, Proc. of Parsons 2007, 7th International Charles Parsons Turbine Conference: Power Generation in an Era of Climate Change, 11-13 Sept. 2007, University of Strathclyde, Glasgow, UK, in press

7 Y. Honnorat, Mater. Tech., 1991, 79, 19-29

8 J. Mao, K.M. Chang, W. Yang, K. Ray, S.P. Vaze and D.U. Furrer, Metall. Mater. Trans. A, 32, 2441-2452.

9 H.T. Pang and P.A.S. Reed, to be published.

10 D .Zheng, A. Rosenberger, H. Ghonem Mater. Sci. Eng. A, 1993, 161, 13-21

11 H.T. Pang and P.A.S. Reed, Int. J. Fat., 2003, 25, 1089-1099

12 M.J. Starink, H. Cama and R.C. Thomson, Scr. Mater., 1997, 38, 73-80.

13 R.C. Thomson and M.J. Starink, US Patent 6219404, 2001.

14 A.J. Manning, D. Knowles, C.J. Small, US Patent Application 20020041821, 2002. 